\title{
Introduction
}

\section{Sexuality in leadership: A long-neglected topic with vast implications for individuals and society}

\section{James K. Beggan and Scott T. Allison}

Sexual opportunities can be construed as a reward for achieving a leadership role (Baumeister, 2010). For some species of animals, social dominance is the sole basis for sexual access to mates (Dixson, 2015). One way that social dominance expresses itself is through leadership. Although becoming a leader may afford sexual opportunities, it is also true that in the twenty-first century, rather than being seen as a benefit, sexuality can be viewed as potential liability for leaders, as people have become more sensitive to issues related to gender, sexual orientation, sexual behavior, and sexual harassment.

There is no shortage of evidence demonstrating that great leaders sometimes have poor judgment when it comes to issues of sexuality (Gamson, 2001). Even a quick glance at the newspapers or history books reveals how many careers have been ruined or irrevocably altered because of sex. Bill Clinton's entire tenure as president can be reduced to a punch line about oral sex. Technically, although guilty of marital infidelity, Bill Clinton's crime with regard to Monica Lewinsky related not to the affair, but to the charges of perjury that stemmed from lying about the affair. Of course, he only lied because he knew there would be a scandal if the affair caught the attention of the media. His perceived wrongdoing stemmed from both the fact that he was married and that Lewinsky was a low-level intern, with far less power than the President of the United States. Elliot Spitzer and Anthony Weiner lost their jobs because of a weakness for prostitutes and sexting, respectively. Retired four-star general and director of the CIA David Petraeus resigned after news of a long-time affair with his biographer became public. Beloved entertainer, civil rights activist, and television surrogate father Bill Cosby had his entire life and career upended after allegations of years of sexual 
misconduct. Donald Trump's presidential race was marred, but ultimately not derailed, by comments he had made years before the election about how being a celebrity entitled him, in his opinion, to make inappropriate sexual advances toward women.

The problems that are created as a result of sex are more systemic than the bad judgment of a few well-positioned leaders. The US military has repeatedly failed to adequately address issues of sexual harassment and sexual assault in its ranks. The Catholic Church turned a blind eye to years of sexual abuse by priests. Fox News became notorious because of a climate of sexual harassment that existed, manifested by the behavior of Fox News CEO Roger Ailes and talk-show host Bill O'Reilly.

In looking at the details of these kinds of cases, we repeatedly ask ourselves two questions: Why do unarguably intelligent and successful leaders put themselves into these kinds of situations? And why are we, as members of the constituency, continually surprised by these revelations? Shouldn't we expect it by now?

Although the question of why rich and powerful men (we are not being sexist here-it is more often men than women) risk their careers by engaging in illicit sexual activity is an interesting one, we suggest that the connection between leadership and sexuality is much more important, complex, and broad than the phenomenon of a sex scandal. Sexual leadership can be viewed as operating at both macro and micro levels. Issues related to sexual leadership come into play when a nation decides in favor of or against an abstinence-only policy with regard to sexual education, the Supreme Court rules in favor of gay marriage, or a husband and wife decide whether to try a new sexual position. Sexual leadership also comes into play in gray and black markets. What leadership dynamics are involved in recruiting, motivating, and managing women who work as strippers, or as prostitutes? The purpose of this edited volume is to explore the largely ignored relationship between sexuality and leadership.

We approach leadership and sexuality from two perspectives. As social scientists, we would like to better understand the way in which human sexuality affects leadership and followship processes. How do sexual dynamics influence how leaders do their jobs? How do sexual dynamics hinder or help with leadership processes? To what degree should leaders initiate policies that address sexual issues? An additional goal is to take on the role of social engineers and apply our knowledge to problems that leaders face with regard to controlling the expression of human sexuality. Ineffective leadership with regard to sexuality can ruin lives. Would better efforts at social engineering ameliorate these problems, and with it create a reduction in human suffering caused by leaders who poorly handle problems associated with leadership and sexuality? 
Our seemingly never-ending surprise that our leaders engage in covert sexual practices or make errors in judgment about issues in a sexual domain can be explained partly by recognizing that it seems almost everyone has trouble talking about sexuality. Even science, or, more accurately, the people who do science, presumably operate through the lens of value-free and objective thinking, yet scholars themselves have issues with sexuality. Social scientists who study sexuality feel their careers are marginalized by more mainstream members of their disciplines (Irvine, 2014). For example, it is more difficult to fund research on sexual science, unless it has a clear medical purpose such as disease prevention.

The focus of this volume is on how power, principles, and processes influence the way that sexuality exerts an influence on leadership and followership. We consider power as the ability to influence an outcome to occur, more specifically with regard to the ability to control resources and others (Stuppy \& Mead, 2017). Leadership and sexuality can both be understood in terms of the expression of power (Parker, Barbosa, \& Aggleton, 2000). Leaders exert influence over followers. People who can influence others often step into leadership roles. Sexual attractiveness can be a means of exerting social influence over another, that is, acting as a leader. Leader status is a characteristic that many people find sexually attractive. Leaders' ability to control others can come about through legitimate as well as illegitimate means. It is typically well within an employer's authority to fire a worker for coming to work late. Quid pro quo sexual relations, on the other hand, are outside the permissible.

A principle can refer to a moral belief about what is right or wrong. Moral judgments decidedly come into play when we evaluate our own and others' sexuality and sexual behavior. Beliefs about sexuality and leadership are often prescriptive in tone, rather than descriptive of what has actually happened or did occur. Principles related to sexuality are often difficult to uphold. Perhaps the clearest instance has to do with the sanctity of marriage. Although marriage is a relationship freely entered into between two consenting adults who a priori promise to make a lifelong commitment to each other ("in sickness and in health and until death do us part"), a significant percentage of marriages end in divorce. Despite some complexities involved in making an estimate (Kennedy \& Ruggles, 2014), an estimate of 50 percent seems reasonable for the United States (Politifact New Jersey, 2012). One of the key elements of traditional marriages is sexual fidelity. Although statistics vary depending on the source, 30-70 percent of men report at least one instance of marital infidelity; about 20-68 percent of women report at least one instance (Thompson \& O’Sullivan, 2016). 
The third concept that is important to consider is the processes involved in understanding the relationship between sexuality and leadership. The processes involved in sexuality can range from micro-processes that last just a few seconds or minutes to macro-level evolutionary processes that have taken literally millions of years to play out. The act of judging someone sexually attractive might take only a second, but factors that influence what processes go into that judgment might have evolved across millions of years.

With regard to sexuality and leadership, we consider principles to be expressed through several prominent theories of sexuality. Sexuality can be viewed as a product of biology, as a psychological process, and as a sociological phenomenon. Biological theories can either focus on the actual process of having sex, as in the case of Masters and Johnson (1966), who studied the stages of sexual arousal, or they can focus on how evolutionary pressures have shaped the way sexual behavior is played out (Buss, 2015). Evolutionary psychology or sociobiology tends to look at the ways in which mate selection processes have evolved over time.

Another class of theories is psychological and focuses on the way people develop certain preferences. A classic example is learning theory, which can be used to consider the way in which an attraction to certain types of stimulation is reinforced (Hogben \& Byrne, 1998). Social exchange theory views sexual behavior in terms of the way people evaluate the costs and benefits of a relationship (Cook, Cheshire, Rice, \& Nakagawa, 2013). Like economics, social exchange theory assumes that actors are (at least mostly) rational actors who try to maximize their potential benefits.

The final approach we consider is sociological and focuses on the way the meaning of sexual activity is socially constructed. A prominent sociological theory of human sexuality is called sexual scripting theory (Simon \& Gagnon, 2003). According to sexual scripting, the most important factor involved in sexuality is the meaning that we as human beings apply to sex. The conceptual basis for sexual scripting theory is symbolic interactionism, which focuses on how people use symbolspredominantly language - to create meaning (Longmore, 1998). From a social constructionist point of view, the importance and nature of sexuality is derived from how we, as a collective culture, choose to see it. Sexual scripts operate at cultural, interpersonal, and intrapersonal levels (Simon \& Gagnon, 2003). At the cultural level, sexual scripts reflect the influence of social institutions such as religion, the law, and mass media. Interpersonal scripts refer to how two or more people negotiate meaning with regard to sexual behaviors. Intrapersonal scripts refer to how an 
individual feels about sexual activities, feelings, or beliefs. Different levels of sexual scripts can be consistent or inconsistent with each other. Consider, for example, kissing. Most people find kissing a pleasurable prelude to sexual activity, and as a result it is not too hard to find other people who might be willing to engage in kissing. Society tends to see kissing as a gesture consistent with both romance and sexuality.

In other instances, there can be conflict between different levels of sexual scripts. As a prominent example, in 2003 when Arnold Schwarzenegger was running for governor of California, a scandal broke because of allegations that he had sexually harassed women (Cohn, Hall, \& Welkos, 2003). After an initial denial, he eventually apologized for the behavior, which had taken place as early as the 1970s and 1980s. The meaning of his actions changed between the end of the twentieth and the beginning of the twenty-first centuries. Womanizing behavior was once not only condoned but, to some, considered heroic for a man in a leadership role. Norms of acceptable leader behavior have shifted and men have been slow to adjust. Donald Trump is a classic example of a male whose sexual misconduct horrified millions of Americans while drawing apathetic responses from millions of others (including some women) who cling to the anachronism that "boys will be boys" (Freedman, 2013).

\section{THE INVENTION OF SEX}

At its most basic level, sex, invented about a billion years ago, is about the exchange of genetic material (Dabhoiwala, 2012). Although the origins of sex can be debated, it can be argued that sex evolved because it created greater variation in offspring, allowed the more rapid spread of beneficial traits, and discouraged the proliferation of harmful traits. In modern society, we have dressed up and romanticized sex so that it appears to involve abstract concepts such as love, beauty, and fidelity but in reality, in its raw form, sex is about influence, coercion, and quite literally survival. Those organisms that managed to have sex and reproduce continued to exist and climb the evolutionary ladder. Those that did not disappeared and now only exist in the fossil record.

Organisms could gain a competitive advantage in two ways (Buss, 1995; Buss \& Schmidt, 1993). Most people know about natural selection, that is, that traits that allow an individual to better adapt to their environment will be selected for and will over time increase in the population. For humans, being stronger, faster, and more intelligent provided an advantage in terms of living long enough first to reproduce 
and second to help one's offspring live long enough to become selfsufficient and then also reproduce. Fewer people recognize the role that sexual selection plays. Sexual selection involves a potential mate expressing a greater willingness to mate with someone on the basis of a trait that person possesses. Organisms that develop traits which those of the opposite sex find more appealing will end up with a greater number of possible mating opportunities. As a result, they will have more children and those descendants will be more likely to have that attractive trait, thus creating a self-reinforcing cycle.

There is a strong association between leadership and sexual success. In some species of animals, the ability to engage in sexual behavior is restricted to only a leader, the alpha male. Leaders can be viewed as positive deviants, in that they are more successful than average. They have more authority than the average member of the species. The link between leadership and sexual access creates a powerful incentive for males to try to become leaders. The desire for sex and the fear of not being able to acquire sex is a powerful motivation that causes people, especially men, to take risks, and can lead to great accomplishment but can also result in great misfortune (Baumeister, 2010). Sexual attractiveness is both a cause and a consequence of leadership. "Power is the ultimate aphrodisiac," Henry Kissinger once observed. This quote carries two meanings. The first might be that being in power increases a person's interest in sex. The second is that people want to have sex with people who wield power.

The characteristics that make someone a good leader may carry over into their sexual desires, beliefs, or actions they are willing to take. A problem occurs when the same trait has different implications in the sexual world. For example, the traits implied in the phrases "I won't take no for an answer" or "I won't give up" are good attributes for a leader but not for a sex partner. The challenge for many leaders is to differentiate leadership attributes that contribute to effective leadership and those that inflate one's sense of entitlement to sexuality.

\section{THE MISMATCH BETWEEN THE MODERN AND ANCIENT WORLDS}

In ancient times, one important aspect of leadership was that it provided access to sexual reproductive opportunities. This may be one of the underlying problems with regard to translating certain principles of leadership to modern society. Mismatches between modern and ancestral environments can occur because we must recognize the concept of an 
environment of evolutionary adaptation (Vugt \& Ronay, 2014). The world that existed when a trait or behavior emerged may not be the same world in which humans live today. Even though the modern world has changed dramatically since ancient times, we as human beings have not evolved as quickly. The assumption of sociobiology is that our hardware, which has evolved over thousands of generations, still exerts an influence on our behavior, even though the influence may no longer be as adaptive.

Culture has helped create mismatches between what is considered appropriate behavior and what preferences might be expressed by evolutionary forces. As noted by MacCannell (2000, p. 249), "Avowed sexualness is, of course, the biggest "no no' for leader and follower alike" for modern democratic groups. MacCannell argued that the Bill ClintonMonica Lewinsky affair can be understood as a conflict between Bill Clinton's belief that his sex life should be kept private and the group's belief that their leader should be asexual. The influence of culture can take many forms, ranging from legal or moral proscriptions to the creation of social or technological inventions designed to contain-or liberate-behavior.

Mismatches can occur for a wide range of reasons. In some cases, there can be a conflict between a desire or preference that may be based on an evolutionary imperative and a restraint that has been placed on people on the basis of societal norms or laws. There can also be a conflict that results from the application of one set of norms or rules in contrast to another set. Both Arnold Schwarzenegger and Donald Trump seemed to be using a "rank has its privileges" motto, a rule that was parodied years earlier in the Mel Brooks song It's Good to be the King. This outdated view of the perks of leadership nonetheless still holds sway in some quarters today. Over periods of time, different rules gain dominance. Conflicts can emerge when rules appropriate to one era are applied in a different one.

Sexual areas tend to create a moral panic which can lead to the imposition of rules, laws, and regulations that may, on the surface, seem like a good idea, but make less sense once they are put into practice. Abstinence-only education has been deemed a failure (Santelli, Ott, Lyon, Rogers, Summers, \& Schleifer, 2006) but was motivated by the belief that any other form of sexual education (such as safer-sex methods of disease or pregnancy prevention) would then increase young adults' tendencies to have sex. Registries for sex offenders, which lead to permanent stigma and have not been shown to produce a reduction in further offending (Agan, 2011), seem contrary to the notion that after a criminal serves his or her time, he or she should enjoy a clean slate to try to be a productive citizen. 
Despite many advances consistent with a liberal agenda that stresses openness, tolerance, and acceptance, in some ways the climate with regard to sexuality has become more repressive and fearful. There is a growing acceptance of sexual orientations and identities that deviate from heterosexual and biologically based. The legalization of gay marriage and support of the rights of transgender people come to mind. At the same time, in the age of the internet and viral videos, where an offended person's first response is often to become outraged and post an angry screed, leaders feel confused and defensive about attitudes toward sexuality.

Mismatches with regard to leaders in the modern and ancient worlds can interfere with leaders' abilities to function effectively, as well as our expectations about them. We have trouble distinguishing between our leaders' personal lives and the tasks they need to perform to function effectively in their role as leaders. This difficulty seems especially relevant when traits or behaviors associated with leadership translate over to domains of sexuality. In her analysis of the Bill Clinton scandal with regard to Monica Lewinsky, MacCannell (2000) noted that the public's attitudes toward Clinton were influenced by an implicit belief that leaders' sex lives belonged in the realm of unspoken territory.

\section{DEALING WITH MISMATCHES: THE DISTINCTION BETWEEN PRACTICE AND REALITY}

In the spring of 2017, we conducted a Google Scholar search for "sexual leadership" which produced only 43 hits. Few of them seemed relevant to our academic goals. Although scholars and policy makers have certainly examined issues related to leadership as well as issues related to sexuality, there has been a notable failure to carry out research under a conceptual umbrella of sexual leadership. Leadership scholars and sexology researchers have not fully addressed problems leaders face at the intersection of human sexual and leadership concerns, despite numerous instances of leaders acting in unethical and even illegal ways with regard to sexual matters. As public awareness about sexually related abuses of leaders has increased, government laws and regulations have increased the culpability of leaders who fail to respond properly to issues involving sexual malfeasance. For example, the Title IX Clery Act requires universities to investigate instances of sexual harassment and carries the threat of fines up to $\$ 35,000$ for the failure to do so.

The tremendous variety in the ways people express their sexuality can create conflicts between individuals, groups, and institutions. Although it is tempting to embrace diversity and defend individuals' right to express 
their sexuality in any way they see fit, certain expressions can be problematic for society and for individuals within society. If we think of ethics as an attempt to create a system of recommendations for how people should live, or a way to distinguish right from wrong, sexual ethics can be viewed as guiding principles for how people should express or restrain their sexual feelings. At one end of the spectrum are sexually related behaviors that most people abhor, such as sexual violence. The other end would include activities that most individuals would see as acceptable, such as sexual activity between consenting married adults. In between those extremes is a large range of behaviors and expressions of sexuality about which people may have strong differences in opinion. These areas could include debates about the appropriate age of consent, the morality of premarital intercourse or infidelity, sexual activity between coworkers, sexual orientation, and the ethics of being consumers or providers of sexual services, such as prostitution.

We suggest that where there is debate, those in disagreement turn to their leaders to establish guiding principles or to enact and enforce rules and laws to govern the expression of sexuality. Leaders have a duty to provide for the well-being of their constituents, with well-being broadly defined to include a consideration of the physical, mental, moral, and spiritual health aspects of sexuality. What is the role of leaders with regard to sexuality? How leaders deal with sexually related issues can influence how they and their organizations are seen by both constituents and outsiders. What we require or demand from leaders with regard to sexuality depends on how we view sexuality. Are sexual desires something we should fight against or succumb to? Should we see sexuality as an outgrowth of our base, animal nature? If so, we need our leaders to protect us from ourselves. A leader can be seen as a moral compass who models appropriate behavior for us by fighting temptation or by creating systems and institutions that assist us in fighting those temptations. Paradoxically, it is also possible to see leaders as those individuals who have challenged outdated beliefs about sexuality and, in the process, allowed us to progress as a society. In other words, some leaders may tempt us to reject the status quo and broaden our definition of acceptable sexual behavior.

\section{OVERVIEW OF THIS VOLUME: LEADERSHIP AND SEXUALITY}

In this book, we distinguish among three categories with regard to sexuality and leadership: (1) sexual leaders; (2) leaders who encounter 
issues related to sexuality; and (3) the sexuality of leaders. We further suggest that leaders need to address issues of well-being by using three distinct strategies: protection, exemplification, and growth. In the present volume, contributing authors address the strategies these types of leaders use to guide their constituents.

Sexual leaders are those leaders who aid individuals in creating and adhering to guiding principles that directly promote sexual well-being. In some instances, these leaders are geared toward protection. For example, policy makers who guide organizations such as Planned Parenthood operate as sexual leaders who are trying to protect their constituents from unwanted pregnancy, sexually transmitted infections, or sexually related assault. In their examination of the history of Planned Parenthood, Sheila Huss and Lucy Dwight discuss how the organization can be viewed as part of a century-long struggle to provide women with an ability to control their own reproductive processes in a way that is free from the threat of criminality or social sanction. The formation of Planned Parenthood began with the pioneering efforts of Margaret Sanger and the organization has seen numerous legal challenges that have included landmark Supreme Court decisions and which continue to this day, with the recent efforts of President Donald Trump to restrict funding to domestic and international agencies that perform abortion or even promote it as an option.

Other sexual leaders can adopt an exemplification strategy and attempt to serve as models for appropriate behavior in a sexual domain. Church officials are viewed as exemplars as sexual leaders by acting as a moral compass for their parishioners. In his autobiographical analysis of the challenges associated with bridging the gap between religion and sexuality, William Stayton combines his more than 50 years of personal experience as an educator with a discussion of science-based efforts to develop training methods to help clergy to become more adept at providing sexually related counseling.

Growth leaders operate like transformational leaders in that they attempt to introduce evolutionary changes in our views of sexual behavior. Sex researchers such as Kinsey and Masters and Johnson can be viewed as growth-oriented leaders because their research findings influenced people to think about human sexuality in new ways. Publishers such as Hugh Hefner, Bob Guccione, and Larry Flynt addressed issues of sexuality through their magazines Playboy, Penthouse, and Hustler. In her analysis of Hugh Hefner as someone who might, at first pass, be seen merely as a staunch defender of hedonism, Carrie Pitzulo makes the argument that he was more than a playboy. He was also an icon and leader because of the way he used his magazine to advance a sexually 
liberal philosophy that included much more than the agenda of heterosexual white males. Starting in Playboy's early years, Hugh Hefnerthrough the medium of his magazine-was also a champion of gay rights and an advocate of women's reproductive rights, in the form of both contraception and abortion. As a counterpoint to Hefner, whose influence has been strongly established over the decades since he founded Playboy, James Beggan uses a qualitative method known as autoethnography to examine the case of a high school student whose protest march for the Free the Nipple movement can be understood as the actions of a young transformational leader.

A second area of analysis involves sexuality and leadership and addresses the way human sexuality intersects with the responsibilities of leaders. Because leaders operate in virtually all areas of human endeavor, but sexuality is a complex topic, leaders must deal with sexuality issues even when they lack clear understanding or training. There has been a long history of leaders who have made poor decisions with regard to sexual issues. Problems leaders face in this regard include dealing with consensual sexual relationships in the workplace, as well as sexual harassment and sexual violence.

In this component of sexuality and leadership, protection takes two forms. Leaders must work to protect employees from unwanted sexual attention. Leaders must also work to protect themselves and the institution they represent from liability associated with unwanted or unsafe sexual practices. Leaders must also act as exemplars for how to behave in sexual ways, even if their area of expertise does not directly involve sexual matters. Consider, for example, David Petraeus, the four-star general who had also served as director of the CIA and who was being considered for a presidential nomination. Petraeus was forced to resign because of an affair he was having with his biographer, Paula Broadwell. Another example of how institutional leaders have failed to cope with the influence of sexuality among their representatives is sexual abuse conducted by Catholic priests and the subsequent cover-up of such activity. Through their efforts of protection and exemplification, leaders can also act to institute changes to sexual policies.

The Jerry Sandusky-Penn State sexual abuse scandal illustrates how people in leadership positions can misuse their institution-based authority to satisfy their own sexual desires. This scandal illustrates a third way in which leaders must address issues related to sexuality. Leaders must protect innocent third parties from potential mistreatment by members of their organizations. The Penn State scandal demonstrates how people in authority can be complicit in these actions by failing to respond appropriately or sufficiently. Although Joe Paterno, the head coach of the 
Penn State football team, followed the necessary protocol after hearing about Jerry Sandusky's behavior, many people argued persuasively that Paterno should have been more proactive in protecting children from Sandusky's abuse. In their analysis of the scandal, Jeremy Fyke, Bree Trisler, and Kristen Lucas describe the scandal as "the cautionary tale" (italics in original) regarding the way leadership needs to be appropriately involved with regard to sexuality in the workplace. They frame the scandal in terms of the need for leaders to communicate effectively about sensitive manners and, perhaps even more importantly, to act in a courageous manner with regard to fulfilling their ethical obligations. Leadership failed because the organization failed to protect constituencies as well as to live up to the high standard we might expect from leaders.

In her chapter on teacher-student sexual relations, Charol Shakeshaft also examines reasons why leaders who encounter instances of educator sexual abuse fail to act. She uses data from a variety of sources, such as depositions, training manuals, student records, and health and mental health records, to better understand administrators' failure to act.

Although companies and organizations can establish their own checks and balances to protect workers, as a society we often turn to the government to enact laws to protect citizens. In an examination of the experiences of gay, lesbian, and bisexual employees, Shaun Pichler notes that they are victims of a significant degree of workplace discrimination, and yet there is no comprehensive federal legislation that prohibits discrimination on the basis of sexual orientation. In his chapter, he examines the way that transformational and heroic styles of leadership can contribute to the implementation of polices geared toward establishing greater fairness toward gay, lesbian, and bisexual employees in the workplace. In the absence of legislation, the actions of forward-thinking leaders can contribute toward the development of greater workplace parity.

Sexuality is often seen as problematic for leaders in business and education settings; as a facet of human behavior that can only lead to difficulties such as personnel conflicts or the threat of lawsuits. But it is important to note that leadership processes are also important in businesses where sexuality is front and center. In her chapter on the leadership processes involved in managing a strip club, Maggie Stone examines how leadership styles such as laissez-faire or autocratic are used in different types of strip clubs. She explores the ways in which the central goal of earning money motivates different classes of employees (managers, strippers, bartenders) and leads to the development of different sorts of structural controls. As she illustrates, different categories of strip clubs make use of different leadership styles, with the goal of 
providing a service to customers but in ways that also ensure the safety of both customers and employees.

The third area of study, the sexuality of leaders, refers to the relationship between a leader's own sexuality and his or her role as leader. As previously stated, Henry Kissinger noted that "power is the ultimate aphrodisiac." The power that leaders possess can make them more desirable in the eyes of others. This power can also increase their level of sexual desire. Power and the trappings of power may also undermine a leader's decision-making competency. In a commentary on the luxurious perks associated with being a general in the US military, former Defense Secretary Robert Gates noted, "There is something about a sense of entitlement and of having great power that skews people's judgment" (Chandrasekaran \& Jaffe, 2012). In an intriguing analysis of the relationship between leadership and sexuality, Emma Turley examines the power dynamics that exist between participants who engage in sex play involving bondage, discipline, sadism, and masochism (BDSM). She adopts the perspective that such behavior is not pathological and instead reflects a complex relationship between power and control for both the dominant and submissive partners. She challenges the notion that the submissive lacks power and only the dominant partner possesses it. Moreover, the power dynamics that exist between the dominant and submissive players can be seen as reflecting on power and authority processes that exist in the larger world outside of BDSM play. She notes that participants tend to be white, well educated, and middle or uppermiddle class. In other words, those who engage in BDSM may in fact be business and community leaders. She also identifies the ways in which BDSM participants take steps to protect themselves from unintended negative consequences.

Leaders can be both victims of processes related to sexuality and also victimizers (knowingly or not). It is possible to view Bill Clinton in several different ways with regard to his leadership and sexuality. First, he can be seen as the victimizer who took advantage of his power as president to unfairly influence Monica Lewinsky into engaging in sexual relations with him. It is also possible to see him as a victim of a concerted Republican effort to impeach him. He can also be seen as a victim of his own foolishness, a man who staked everything on a brief sexual thrill and, in the process, turned his presidency into a punch line. In an analysis of the Bill Clinton-Monica Lewinsky scandal, James Beggan adopts a contrarian position with regard to Bill Clinton's decision-making skills. On the basis of an analysis of the likelihood of getting found out, as well as the possible hedonistic value of the affair, he 
argues that Bill Clinton's decision should not be automatically viewed as poorly thought out.

\section{THE CHALLENGE OF SEXUALITY FOR LEADERS}

Because of taboos associated with sexuality, leaders may be unable or unwilling to deal with issues related to sexual behavior. Advice given to leaders about sexuality often frames it as a negative-something to be defended against, minimized, or even ignored. This strategy can backfire, because the issues do not go away just because people pretend they do not exist. Those same taboos often make it difficult to get clear information about sexual behavior. Sex talk aimed at leadership often has a defensive tone-that is, it might focus on how to avoid sexual harassment or sexual harassment lawsuits. Another problem is that attitudes about sexually related matters can change very rapidly. Attitudes about gay marriage, the rights of transgender people, and the expression of sexuality are changing, and sometimes quickly. How are leaders going to navigate the evolving terrain?

Two forces combine to create a great dilemma for leaders. One force is the acceptance of unrealistic expectations. For example, we have created a culture that valorizes marital fidelity, even though we realize that by objective standards, that goal is difficult to attain. Depending on the source and whether we are talking about men or women, between 20 and 70 percent of individuals have been willing to engage in infidelity. Despite this baseline, research indicates we feel we are better than others at resisting sexual temptation (Garos, Beggan, \& Kluck, 2005). We also think we are better sex partners than others (Beggan, Vencill, \& Garos, 2013). In other words, we possess unwarranted optimism about our virtue in sexual domains.

The other force that operates is the actor-observer difference (Nisbett, Caputo, Legant, \& Marecek, 1973), wherein people tend to explain their own behavior differently than they explain the behavior of others. In certain situations, we have more tolerance for our failures than for the failures of others. We might be inclined to attribute others' extra-marital affairs to their characterological flaws. With ourselves, we would tend to attribute our sexual indiscretions to situational circumstances. We are unfaithful because our spouse does not understand us; they are unfaithful because they are bad people. We are quick to turn on our leaders for sexual indiscretions, even though we might do the same thing given the same circumstances. Our leaders know this, of course, so when they are caught, they are quick to deny it. If and when the truth comes out, we 
are quick to condemn them for lying, even though our unrealistic expectations have contributed to them lying to us in the first place.

The difficulty that leaders experience negotiating in the sexual domain may be compounded when recommendations to leaders or by leaders represent unrealistic solutions at odds with basic principles about human nature. Policies related to sexuality often have a moralistic tone, which can ultimately be unrealistic and therefore, rather than creating a solution, merely creates more problems. Consider the example of two employees of the same company who have a sexual attraction to each other. The fear of interpersonal conflict, compounded by a fear of potential litigation, leads a company's decision makers to simply devise a policy that forbids workplace romantic relationships. Does a proclamation that employees cannot date colleagues prevent workplace romance? Maybe in some cases that policy will succeed, but a host of basic psychological principles argue against it. What it really does is drive the dating process underground, where people hope and think they can avoid detection. But what happens is that the secrecy is both worrisome and exciting. Paradoxically, the ban can increase the frequency and intensity of the problem (Wegner, 1989).

The difference between what people portray a sexually related situation as and the other practices or processes which may be going on beneath the surface is explored in the chapter on sexuality in relationship to social dancing. James Beggan and Scott Allison examine the phenomenon of social dancing with regard to the way in which a dichotomous definition of sex (as male or female) plays into the assignment of roles (as lead or follow) in social dancing. They also explore the way in which dancers may downplay the role that sexual desire or sexual attraction plays in motivating the desire to social dance.

Throughout the animal kingdom, sexual behaviors are conducted in the service of reproductive goals that will enhance the survival of the species. For modern humans, particularly those dwelling in developed nations, the urgency of the reproductive goal has been minimized. Our entertainment industry provides a vicarious experience of reproductive urgency in the television series The Walking Dead. Scott Allison and Olivia Efthimiou focus on the heroic self-sacrifice of bringing children into the postapocalyptic world of lawlessness, hunger, and brutality. The decision to reproduce illustrates heroism and heroic leadership at two different levels of analysis. First, the choice to have children in the post-apocalyptic world reflects heroic self-sacrifice on the part of the individual decision maker (Allison \& Goethals, 2011). A woman who chooses to have a child in a world with no formal healthcare system risks her own physical wellbeing. Second, the choice to repopulate the broken world of The 
Walking Dead also reflects a system-wide societal drive toward regeneration and restoration. The decision to reproduce thus reflects the heroic embodiment of human society as an organism intent on surviving and even flourishing.

Leaders have to "do sexuality," but sexuality is also "done to them." This occurs at both a personal and an institutional level. As leaders operating with a fiduciary responsibility to their constituents, they have to take a proactive rather than a reactive stance and put institutional mechanisms into place to deal with sexual issues. As individuals who happen to be leaders, they may possess and act on and respond to others' actions as sexual beings. Problems occur when the distinction between these two levels becomes blurred. We hope the chapters in this book will provide guidance and also light the way for further scholarly work on the relationship between sexuality and leadership.

\section{REFERENCES}

Agan, A. Y. (2011). Sex offender registries: Fear without function? The Journal of Law and Economics, 54(1), 207-39.

Allison, S. T., \& Goethals, G. R. (2011). Heroes: What they do \& why we need them. New York: Oxford University Press.

Baumeister, R. F. (2010). Is there anything good about men? How cultures flourish by exploiting men. New York: Oxford University Press.

Beggan, J. K., Vencill, J. A., \& Garos, S. (2013). The good-in-bed effect: College students' tendency to see themselves as better than others as a sex partner. The Journal of Psychology, 147(5), 415-34.

Buss, D. M. (1995). Evolutionary psychology: A new paradigm for psychological science. Psychological Inquiry, 6(1), 1-30.

Buss, D. M. (2015). Evolutionary psychology: The new science of the mind (5th ed.). New York: Routledge.

Buss, D. M., \& Schmitt, D. P. (1993). Sexual strategies theory: An evolutionary perspective on human mating. Psychological Review, 100(2), 204-32.

Chandrasekaran, R., \& Jaffe, G. (2012, November 17). Petraeus scandal puts four-star general lifestyle under scrutiny. The Washington Post. Retrieved September 18, 2017 from https://www.washingtonpost.com/world/nationalsecurity/petraeus-scandal-puts-four-star-general-lifestyle-under-scrutiny/2012/ 11/17/33a14f48-3043-11e2-a30e-5ca76eeec857_story.html?utm_term=.486fb3 c103a9

Cohn, G., Hall, C., \& Welkos, R. W. (2003). Women say Schwarzenegger groped, humiliated them. Los Angeles Times. Retrieved May 20, 2017 from http://articles.latimes.com/2003/oct/02/local/me-women2.

Cook, K. S., Cheshire, C., Rice, E. R., \& Nakagawa, S. (2013). Social exchange theory. In J. DeLamater \& A. Ward (Eds.), Handbook of social psychology (2nd ed.) (pp. 61-88). New York: Springer. 
Dabhoiwala, F. (2012). The origin of sex: A history of the first sexual revolution. New York: Penguin Books.

Dixson, A. (2015). Primate sexuality. In P. Whelehan \& A. Bolin (Eds.), The international encyclopedia of human sexuality (pp. 343-50). New York: Wiley.

Freedman, E. B. (2013). Redefining rape: Sexual violence in the era of suffrage and segregation. Cambridge, MA: Harvard University Press.

Gamson, J. (2001). Normal sins: Sex scandal narratives as institutional morality tales. Social Problems, 48(2), 185-205.

Garos, S., Beggan, J. K., \& Kluck, A. (2005). Temptation bias: Seeing oneself as better able than others to resist temptation. Research in the Scientific Study of Religion, 15, 235-61.

Hogben, M., \& Byrne, D. (1998). Using social learning theory to explain individual differences in human sexuality. Journal of Sex Research, 35(1), $58-71$.

Irvine, J. M. (2014). Is sexuality research "dirty work"? Institutionalized stigma in the production of sexual knowledge. Sexualities, 17(5-6), 632-56.

Kennedy, S., \& Ruggles, S. (2014). Breaking up is hard to count: The rise of divorce in the United States, 1980-2010. Demography, 51(2), 587-98.

Longmore, M. A. (1998). Symbolic interactionism and the study of sexuality. Journal of Sex Research, 35(1), 44-57.

Masters, W. H., \& Johnson, V. E. (1966). Human sexual response. Boston, MA: Little, Brown.

MacCannell, J. F. (2000). Politics in the age of sex: Clinton, leadership, love. Cultural Critique, 46(Fall), 241-71.

Nisbett, R. E., Caputo, C., Legant, P., \& Marecek, J. (1973). Behavior as seen by the actor and as seen by the observer. Journal of Personality and Social Psychology, 27(2), 154.

Parker, R., Barbosa, R. M., \& Aggleton, P. (2000). Framing the sexual subject: The politics of gender, sexuality, and power. Berkeley, CA: University of California Press.

PolitiFact New Jersey. (2012, February 20). Steve Sweeney claims two-thirds of marriages end in divorce. Truth-O-Meter. Retrieved May 19, 2017 from http:// www.politifact.com/new-jersey/statements/2012/feb/20/stephen-sweeney/stevesweeney-claims-more-two-thirds-marriages-end/

Santelli, J., Ott, M. A., Lyon, M., Rogers, J., Summers, D., \& Schleifer, R. (2006). Abstinence and abstinence-only education: A review of US policies and programs. Journal of Adolescent Health, 38(1), 72-81.

Simon, W., \& Gagnon, J. H. (2003). Sexual scripts: Origins, influences and changes. Qualitative Sociology, 26(4), 491-97.

Stuppy, A., \& Mead, N. L. (2017). Heroic leaders and despotic tyrants: How power and status shape leadership. In S. T. Allison, G. R. Goethals, \& R. M. Kramer (Eds.) Handbook of heroism and heroic leadership (pp. 476-94). New York: Routledge.

Thompson, A. E., \& O'Sullivan, L. F. (2016). Drawing the line: The development of a comprehensive assessment of infidelity judgments. Journal of Sex Research, 53(8), 910-26.

Vugt, M. V., \& Ronay, R. (2014). The evolutionary psychology of leadership: Theory, review, and roadmap. Organizational Psychology Review, 4(1), 74-95. 
Wegner, D. M. (1989). White bears and other unwanted thoughts: Suppression, obsession, and the psychology of mental control. London: Guilford Press. 